\title{
Effect of microstructural parameters on the mechanical behavior of TiAlNb(Cr,Mo) alloys with $\gamma+\sigma$ microstructure at ambient temperature
}

\author{
Michael S. Kesler, Sonalika Goyel, Fereshteh Ebrahimi, Michele V. Manuel
}

University of Florida, Materials Science and Engineering, P.O. Box 116400, Gainesville, FL 32611, USA

* Corresponding author

mmanuel@mse.ufl.edu

Phone: 352-846-3780; Fax: 352-392-7219

\begin{abstract}
The mechanical properties of novel alloys with two-phase $\gamma-\mathrm{TiAl}+\sigma-\mathrm{Nb}_{2} \mathrm{Al}$ microstructures were evaluated under compression at room temperature. Microstructures of varying scales were developed through solutionizing and aging heat treatments and the volume fraction of phases were varied with changes in composition. Ultra-fine, aged $\gamma+\sigma$ microstructures were achieved for the alloys which affectively retained high volume fractions of the parent $\beta$-phase upon quenching from the solutionizing temperature. The yield strength and compressive strain to failure of these alloys show a strong dependence on the relative scale and volume fraction of phases. Surprisingly, the hard brittle $\sigma$ phase particles were not found to control fracture in the refined microstructures.
\end{abstract}

Keywords: titanium aluminides, age hardening, mechanical properties, inhomogeneous deformation 


\section{Introduction}

Titanium aluminides with $\gamma+\alpha_{2}$ microstructures are currently being incorporated into aerospace turbine engines because these alloys have a low density in the range of $3.7-4.5 \mathrm{~g} / \mathrm{cm}^{3}$, in comparison to Ni-base superalloys (density range of $8-9 \mathrm{~g} / \mathrm{cm}^{3}$ ) [1]. The yield strength of these alloys decreases at approximately $750^{\circ} \mathrm{C}$, limiting applications to less extreme environments in high performance turbines [1-3]. The improvement of high temperature properties of $\gamma$-TiAl alloys while preserving ductility and toughness at ambient temperature is of significant interest to researchers in this area.

Microstructure has proven to play an important role in the enhancement of strength and ductility in these alloys. The fully lamellar (FL) and duplex (DP) microstructures have attracted the most attention [4-7]. The FL microstructure consists of grains of $\alpha$-phase that transform to a $\gamma+\alpha_{2}$ lamellar microstructure upon cooling. This microstructure has been shown to provide excellent toughness up to $30 \mathrm{MPam}^{1 / 2}$, strength exceeding $1000 \mathrm{MPa}$ and acceptable high temperature properties up to $750^{\circ} \mathrm{C}$, but has limited ductility at room temperature (RT). The properties are optimized when the $\alpha$ grain size, lamellar colonies, and inter-lamellar spacing are altered $[3,6,8,9]$. The limited work temperature prohibits these materials from expanding to more extreme regions of the turbine engine.

Efforts have been undertaken that incorporate hard particles such as oxides, borides, and silicides into the various $\gamma+\alpha_{2}$ microstructures to further enhance high temperature properties [10-12]. These materials are usually prepared by powder metallurgy with pre-existing hard particles prior to sintering. Crack initiation at the particle/matrix interface becomes problematic at RT for many of these alloys resulting in lower toughness and a loss of tensile ductility. Finding a balance in room and high temperature mechanical properties for dispersion strengthened TiAl alloys has proven difficult.

In light of the limitations that exist with the $\alpha_{2}$-phase and additions of hard dispersoids, alternative alloys with high $\mathrm{Nb}$-content are explored in this study which lie in the two phase $\gamma$-TiAl $+\sigma-$ 
$\mathrm{Nb}_{2} \mathrm{Al}$ region [13-19]. The $\sigma$-phase is hard and has been shown to provide excellent creep resistance in TiAlNb alloys, but RT toughness and ductility are poor when this phase is connected and present in high volume fractions [13-16]. This phase has not shown to deform until reaching temperatures in excess of $900^{\circ} \mathrm{C}[14]$. Additional benefits of $\mathrm{Nb}$ in $\gamma$ alloys come from improved processability and strengthening in the $\gamma$-phase which include solid solution strengthening and modifications to the deformation mechanisms [20-25].

In this study, Ti-45Al-xNb-based alloys (where $\mathrm{x}=14,18$, and 22 at $\%$ ) with additions of 5 at $\%$ $\mathrm{Cr}(5 \mathrm{Cr})$ and/or $1 \mathrm{at} \% \mathrm{Mo}(1 \mathrm{Mo})$ were designed, based on the most recent optimization of the Ti-Al$\mathrm{Nb}$ phase diagram [26], to consist of a microstructure with a single solid solution $\beta$-phase between $1400-1500^{\circ} \mathrm{C}$. An isopleth section of the Ti-Al-Nb ternary at $45 \% \mathrm{Al}$ with alloys indicated is shown in Fig. 1. Upon quenching to RT, the $\beta$-phase provided a metastable parent phase from which the $\gamma+\sigma$ precipitation could be controlled by aging at various temperatures $\left(865,1000,1050\right.$, and $\left.1100^{\circ} \mathrm{C}\right)[17$ 19, 27]. Relevant details of the three phases of interest are presented in Table 1. Compression testing was conducted to elucidate how microstructural parameters, such as volume fraction and size of the phases affect plastic deformation and fracture behaviors.

\section{Materials and Experimental Procedures}

Four alloys with nominal compositions of Ti-45Al-22Nb-5Cr $(22 \mathrm{Nb}+\mathrm{Cr})$, Ti-45Al-18Nb-5Cr1Mo (18Nb+CrMo), Ti-45Al-14Nb-5Cr-1Mo (14Nb+CrMo) and Ti-45Al-18Nb (18Nb) (all compositions are given in at $\%$ ) were melted into $10 \mathrm{~g}$ buttons in a non-consumable tungsten arc-melter on a custom water-cooled copper hearth with flowing argon. To ensure compositional homogeneity during melting, each sample was melted and flipped 6 times in $5 \mathrm{~g}$ buttons, then combined to $10 \mathrm{~g}$ and melted twice more. Compression samples were made manually by cutting out rectangular specimens 
with a height to width ratio of 1.5 and dimensions of $4 \times 4 \times 6 \mathrm{~mm}$ using a slow speed saw with a diamond blade from the as-cast material.

Compression samples were then wrapped in a single layer of Ta foil with a thickness of $\sim 100$ $\mu \mathrm{m}$ for the solutionizing heat treatment. A clam-shell furnace, capable of reaching $1600^{\circ} \mathrm{C}$, was ramped at rate of $9^{\circ} \mathrm{C} / \mathrm{min}$ and held for $1 \mathrm{hr}$ (from 1400 to $1500^{\circ} \mathrm{C}$ ) above the $\beta$ to $\gamma$ phase transformation temperature $[19,26]$. The furnace was custom fit with a sealed alumina tube for a controlled environment and drop-quenching capabilities allowing samples to be water quenched (WQ) from the solutionizing temperature. A roughing pump was applied to evacuate the tube and the system was purged with Ti-gettered ultra high purity Ar gas that flowed through for the duration of the heat treatments.

Electron probe microanalysis (EPMA) was conducted, using a JEOL Superprobe 733, on samples after the solutionizing+WQ heat treatment and measured compositions of each alloy are given in Table 2. Samples were then encapsulated in quartz tubes and backfilled with Ar gas and aged at various temperatures $\left(865\right.$ to $\left.1100^{\circ} \mathrm{C}\right)$ and furnace cooled (FC) to arrive at the final microstructures.

After aging, the compression samples (1-2 tests per aging condition for each alloy composition) were planed and polished on all sides down to a $0.3 \mu \mathrm{m}$ finish using standard metallographic techniques. The tests were conducted on a hydraulic MTS load frame with a 20 kip load cell at room temperature. The crosshead speed was kept constant for all samples tested resulting in initial strain rates ranging from $3.9 \times 10^{-4}$ to $4.9 \times 10^{-4} \mathrm{~s}^{-1}$ depending on the initial sample height. The majority of samples were loaded to fracture while selected samples were unloaded at a low plastic strain to investigate the early stages of plastic deformation as well as crack initiation and propagation.

Phase identification was achieved through $\mathrm{x}$-ray diffraction (XRD) analysis using a Philips APD $3720 \mathrm{x}$-ray diffractometer with a $\mathrm{Cu}$ anode $\left(\mathrm{K}_{\mathrm{a} 1}=1.54056 \mathrm{~nm}, \mathrm{~K}_{\mathrm{a} 2}=1.54439 \mathrm{~nm}\right), 2$ theta range 
of 20-130 degrees, 0.07 degree step size, and 2 seconds per step. Samples were milled into powders for XRD measurements because of the crystallographic texturing and large grains encountered in the microstructure of the alloys studied. A light optical microscope (LOM) and an FEI xL40 field emission scanning electron microscope (FESEM) were employed for microstructural and fracture analyses. Individual phases in the two-phase $\gamma+\sigma$ microstructure were identified based on the phase contrast in the backscattered electron (BSE) images. ImageJ software was employed for quantitative metallography, while microstructural parameters including mean random spacing of $\sigma$-phase particles, $\sigma_{\mathrm{r}}$, mean-free path, $\lambda$, and mean particle diameter were measured and calculated as described by Underwood [28]. While co-precipitated $\sigma$-phase particles are not necessarily regular in shape, this method permitted comparison across samples in a regular methodology. An etchant with $55 \% \mathrm{H}_{2} 0+$ $25 \% \mathrm{HF}+20 \% \mathrm{HNO}_{3}$ was applied for revealing microstructure in samples prepared for LOM.

\section{Results}

3.1 Microstructural Analysis

\subsubsection{Solutionized+WQ Alloys}

Figs. 2(a), (c), (e), and (g) show LOM images of the microstructures of the four alloys, Alloy $22 \mathrm{Nb}+\mathrm{Cr}$, Alloy $18 \mathrm{Nb}+\mathrm{CrMo}$, Alloy $14 \mathrm{Nb}+\mathrm{CrMo}$, and Alloy $18 \mathrm{Nb}$, respectively, after undergoing a solutionizing $+\mathrm{WQ}$ heat treatment. Alloy $22 \mathrm{Nb}+\mathrm{Cr}$ consists of a single phase as shown in Fig. 2(a).

The XRD profile, given in Fig. 2(b) identifies this as the $\beta$-phase. Though, no other phases have been observed through SEM or identified using XRD, a metastable Orthorhombic-phase (labeled as O in Figure 2(f) and 2(h)) is known to transform out of the $\beta$-phase after cooling of alloys with similar composition [17, 29]. Additionally, low volume fraction and XRD peak overlap with the $\beta$-phase further obscures clear evidence of the presence of this phase. 
Alloy $18 \mathrm{Nb}+\mathrm{CrMo}$ and Alloy 14Nb+CrMo, in Fig. 2(c) and Fig. 2(e), respectively, consist of large grains similar to Alloy $22 \mathrm{Nb}+\mathrm{Cr}$, but show the Widmanstätten structure of the $\gamma$-phase at the $\beta$ phase grain boundaries. In comparison to Alloy $22 \mathrm{Nb}+\mathrm{Cr}$, the larger amounts of the $\gamma$ - and Orthorhombic-phases in Alloy $18 \mathrm{Nb}+\mathrm{CrMo}$ and Alloy $14 \mathrm{Nb}+\mathrm{CrMo}$ made it possible to detect in the XRD profiles, as shown in Fig. 2(d) and Fig. 2(f). While the $\beta$-phase was largely retained in the bulk of these alloys the formation of the $\gamma$-phase could not be entirely prevented.

Fig. 2 (g) shows a LOM image of large $\beta$ grains in Alloy $18 \mathrm{Nb}$, though the XRD profile in Fig. 2(h) shows that very little of the $\beta$-phase has been retained. The large $\beta$-grains are evidence of a single high temperature phase, but upon quenching, the rapid transformation to the $\gamma$-phase in this alloy reveals the need for the addition of $\beta$-stabilizers present in the other alloys in this study.[17, 19, 26]

\subsubsection{Aged Samples}

Fig. 3 displays seven $\gamma+\sigma$ microstructures, wherein the $\sigma$-phase has a high $\mathrm{Nb}$ content resulting in a lighter appearance due to a high Z-contrast compared to the $\gamma$-phase. The microstructural parameters for all the alloys at a given aging treatment are listed in Table 3. The microstructures in Fig. 3(a) and Fig. 3(b) are from Alloy 22Nb+Cr after aging each sample for 2 hrs at 865 and $1050^{\circ} \mathrm{C}$, respectively. The sample aged at $865^{\circ} \mathrm{C}$ has a finer microstructure than the sample aged at $1050^{\circ} \mathrm{C}$, while the volume fraction remains constant at approximately $0.3 \sigma$-phase at both temperatures. XRD of $22 \mathrm{Nb}+\mathrm{Cr}$ aged at $1050^{\circ} \mathrm{C}$ is presented in Fig. 4, evidencing a fully $\gamma+\sigma$ alloy. A thermodynamic re-assessment of the Ti-Al-Nb ternary phase diagram [26] reveals limited changes in $\gamma$ - and $\sigma$-phase compositions and volume fractions across the aging temperature range employed in this study which is consistent with the quantitative microscopy results presented here in Table 3. Similar results are observed in Alloy 18Nb+CrMo and Alloy 14Nb+CrMo, Fig. 3(c) and (d), and Fig. 3(e) and (f), respectively, showing measurably similar volume fraction and increasing $\sigma$-phase particle diameter 
with aging temperature for a given alloy. For these three alloy compositions, the measured $\sigma$-phase particle diameter at a given aging temperature increases with increasing $\sigma$-phase volume fraction. One major difference in the $\sigma$-phase morphology occurs in Alloy $22 \mathrm{Nb}+\mathrm{Cr}$ heat treated at $1050^{\circ} \mathrm{C}$ where the $\sigma$-phase is interconnected likely due to the high volume fraction and growth of this phase to the point where particles begin to impinge on each other (Fig. 3(b)).

Alloy $18 \mathrm{Nb}$ was aged for $2 \mathrm{hrs}$ at $1100^{\circ} \mathrm{C}$ and resulted in the coarsest $\sigma$ - and $\gamma$-phases (Fig. $3(\mathrm{~g}$ ) and Table 3) as a result of the inability to retain the $\beta$-phase during the solutionizing and WQ heat treatment. Alloy $18 \mathrm{Nb}$, similar to Alloy $14 \mathrm{Nb}+\mathrm{CrMo}$, has a volume fraction of approximately $0.12 \sigma-$ phase. The aged microstructure showed a distribution of $\sigma$-phase particles located primarily at the relatively coarse $\gamma$-phase boundaries. The similar $\sigma$-phase volume fraction, despite lower $\mathrm{Nb}$-content, is consistent with previous results and site occupancy studies $[17,18]$ where $\mathrm{Al}$ preferred to exist at approximately 50 at $\%$ in the $\gamma$-phase, while $\mathrm{Nb}$ substituted for Ti. During aging, $\mathrm{Cr}$ and, to a lesser extent, $\mathrm{Nb}$ are rejected by the $\gamma$-phase resulting in a $\mathrm{Cr}$-rich parent $\beta$-phase which ultimately transforms to the $\sigma$-phase. Experimentally, the $\sigma$-phase has shown a higher solubility for $\mathrm{Cr}$ than the $\gamma$ phase in these $\gamma+\sigma$ alloys.

\subsection{Compression testing}

Samples aged at $865,1000,1050$, and $1100^{\circ} \mathrm{C}$ for $2 \mathrm{hrs,} \mathrm{were} \mathrm{tested} \mathrm{under} \mathrm{compression} \mathrm{at} \mathrm{room}$ temperature and the stress-strain curves are presented in Fig. 5. Table 4 is a summary of relevant mechanical properties for each individual specimen tested. Yielding preceded fracture in all samples tested. For a given alloy composition, the fine scale of the microstructure for specimens aged at $865^{\circ} \mathrm{C}$ resulted in the highest yield strengths and lowest fracture strains. Conversely, the coarsest microstructures aged at $1050^{\circ} \mathrm{C}$ and $1100^{\circ} \mathrm{C}$ resulted in the lowest yield strengths and highest strains to failure, for a given composition. 


\subsection{Fractography}

At a macroscopic level, fracture of the alloys in this study generally followed a combination of transgranular and intergranular fracture through the prior $\beta$ grains and prior boundaries (shown in Fig. 6(a) and (b)), with the exception of Alloy 18Nb. Fig. 6(a) exhibits a montage of low magnification LOM pictures from a compression sample of Alloy $22 \mathrm{Nb}+\mathrm{Cr}-1050$, which clearly shows the prior $\beta$ grains inherited from the solutionized microstructure. In this sample, both fracture paths can be identified. The proportion of the intergranular fracture could be correlated with the orientation of the prior $\beta$ grain boundaries relative to the loading axis. When boundaries were near parallel to the compression axis, i.e. perpendicular to the anticipated maximum global tensile stress, fracture predominantly took place at the prior $\beta$ grain boundaries. The intergranular fracture in a completely fractured sample of Alloy $22 \mathrm{Nb}+\mathrm{Cr}-865$ is shown in Fig. 6(b), where the fracture surface exhibits part of a prior $\beta$ grain. The high magnification inset in Fig. $6(\mathrm{~b})$ reveals that the actual fracture path is not smooth and the crack follows a tortuous path through the $\gamma+\sigma$ microstructure in the vicinity of the prior $\beta$ grain boundaries. This macroscopic fracture path suggests that the prior $\beta$ grain boundaries control the fracture of these alloys. The prior $\beta$ grain boundaries were not observed to have played a role in the macroscopic fracture path of Alloy $18 \mathrm{Nb}$, but cannot be ruled out as a possible fracture initiation site. Further characterization of the deformation and micro-crack evolution at the prior $\beta$ grain boundaries of all the alloys is necessary to fully understand the nature of fracture in these materials.

Two rectangular compression samples, from Alloy $14 \mathrm{Nb}+\mathrm{CrMo}$ aged at $1000^{\circ} \mathrm{C}$ and Alloy $18 \mathrm{Nb}$ aged at $1100^{\circ} \mathrm{C}$, were loaded to small plastic strains and unloaded repeatedly until microcracking occurred in the center of a prior $\beta$ grain in the uniform $\gamma+\sigma$ microstructure and could be observed in the SEM. The stress-strain curves for these two tests are shown in Fig. 7(a) and (b) overlaid on a curve generated from an identical specimen tested to fracture to show consistency 
between samples. The purpose of this experiment was to induce micro-cracking to develop an understanding of the relationship between microstructure and damage evolution in relatively fine $\left(14 \mathrm{Nb}+\mathrm{CrMo}\right.$ aged at $\left.1000^{\circ} \mathrm{C}\right)$ and coarse $\left(18 \mathrm{Nb}\right.$ aged at $\left.1100^{\circ} \mathrm{C}\right) \gamma+\sigma$ microstructures of similar volume fraction ( 0.13 nominal $\sigma$-phase volume fraction) but very different microstructural morphologies.

\section{Discussion}

\subsection{Effect of $\gamma$-phase formation during quenching}

The aged microstructures away from the prior $\beta$ grain boundaries, in Figs. 3(a-f), formed with a high driving force for nucleation from the metastable $\beta$-phase upon aging, resulting in relatively fine microstructures. The $\gamma+\sigma$ microstructure transforms very rapidly out of the metastable $\beta$-phase in alloys within this compositional range [19]. The fine microstructures in Alloy $22 \mathrm{Nb}+\mathrm{Cr}$, Alloy $18 \mathrm{Nb}+\mathrm{CrMo}$, and Alloy $14 \mathrm{Nb}+\mathrm{CrMo}$, are attributed to the formation of the $\gamma$ - and $\sigma$-phases at similar temperatures upon aging that limited the growth of the phases. The increased aging temperature lead to coarsening of the microstructure. This is evidenced by the constant volume fractions measured in the samples aged at 865 and $1050^{\circ} \mathrm{C}$. In Alloy $22 \mathrm{Nb}+\mathrm{Cr}$, as the microstructure coarsens from the aging temperature of 865 to $1050^{\circ} \mathrm{C}$, a connected $\sigma$-phase is created (Fig. 3(b)). A coarse connected $\sigma$-phase can result in poor mechanical properties at ambient temperature $[15,16]$ and this is evident in this alloy by the limited failure strain particularly compared to the other alloys aged at $1050^{\circ} \mathrm{C}$ in Table 4 .

The microstructure of the Alloy $18 \mathrm{Nb}$ in Fig 3(g) is significantly coarser than the other alloys because it evolved from an entirely $\gamma+\beta$ structure which formed at high temperature during the quenching process, as seen in Fig. 2(h), due to the rapid transformation of the $\gamma$-phase in this particular alloy. The $\beta$-phase in this alloy was not stabilized with additional alloying elements [18]. As this preexisting $\gamma$-phase was aged, there was more time for growth before the $\sigma$-phase nucleated. Once $\sigma$ - 
phase nucleation began, the amount of retained $\beta$-phase was limited such that nucleation sites for the $\sigma$-phase were reduced, resulting in enhanced growth and a coarser particle. To control the scale of $\gamma+\sigma$ microstructures, the $\beta$-phase must be quenched-in prior to precipitation of the $\gamma$ and $\sigma$ phases.

\subsection{Effect of volume fraction}

When analyzing the effect of volume fraction it is important to limit the comparisons to alloys at constant aging temperatures so that the factors that affect the measured properties are limited. Also, it should be understood that there are many factors that dictate the behavior of an alloy, including, but not limited to composition of phases, particle/matrix coherency, and scale, so the following is an attempt to isolate the effect of the volume fraction of phases. As a general trend, the yield strength increased and the strain to failure decreased as the volume fraction of the $\sigma$-phase was increased. The sample displaying the greatest yield strength at $0.22 \sigma$-phase volume fraction $(18 \mathrm{Nb}+\mathrm{CrMo}-865$ with $\sigma_{y}=2140 \mathrm{MPa}$ ) was the exception to the trend. This apparent inconsistency shows that while the volume fraction of the $\sigma$-phase plays a role in the strength, other factors can be employed to optimize the mechanical properties of these alloys. This particular result was attributed to the mean diameter of the $\sigma$-phase in each sample $(0.08 \mu \mathrm{m}$ in $18 \mathrm{Nb}+\mathrm{CrMo}-865$ and $0.14 \mu \mathrm{m}$ in $22 \mathrm{Nb}+\mathrm{Cr}-865)$.

In previous studies $[14,15,30]$ where $\gamma+\sigma$ alloys had volume fraction of the $\sigma$-phase that varied from 0.5 to 0.7 , the alloys fractured in the linear elastic region and the fracture strength was consistent (ranging from 1861 to $1911 \mathrm{MPa}$ ) over this range of $\sigma$-phase content. Although these alloys had coarser microstructures than the alloys in this study, the $\sigma$-phase was a connected matrix and so the compressive strength of the material seemed to be governed by the strong brittle matrix.

Interestingly, when the volume fraction of the $\sigma$-phase was significantly reduced for the current study, the yield strengths were equal to (Alloy $22 \mathrm{Nb}+\mathrm{Cr}-865)$ or above $(18 \mathrm{Nb}+\mathrm{CrMo}-865)$ that of the alloys with very high relative volume fractions of the hard $\sigma$-phase $(<0.5-0.7)$.[26] In addition, high relative 
$\sigma$-phase alloys [26] showed that when an alloy has a two-phase $\beta+\sigma$ microstructure with comparable $\sigma$-phase volume fraction ( 0.7), then the yield strength precipitously drops (ranging from 1315 to 1422 $\mathrm{MPa})$. The explanation for this drop in fracture strength had been associated with the change in composition in the $\sigma$-phase. However, like the alloys of the current study, the low relative yield strength of the $\beta$-phase, which undergoes extensive plasticity, maybe the cause of premature fracture in the $\beta+\sigma$ alloy. It is proposed here that while the relative high strength of all the alloys mentioned are a result of the presence of the $\sigma$-phase, the extent of the strength achieved is governed by the onset of plasticity in the more ductile phase present within the microstructure. As a result, the alloys with high volume fractions of a connected $\sigma$-phase [26] fracture soon after the onset of plasticity in the ductile particles because only a small volume of material can accommodate the plastic strain. The alloys in the current study have a greater capacity to accommodate the local strains which occur upon the onset of plastic deformation in the $\gamma$-phase matrix. In the alloys in the current study, the high strength has been retained, and with lower volume fraction of the brittle phase, the alloys appear more ductile and likely have been toughened significantly compared to alloys with a high relative volume fraction of the $\sigma$ phase.

\subsection{Effect of microstructural scale}

Fig. 8(a) and Fig. 8(b) show the variation of yield strength with $\sigma$-particle size and aging temperature, respectively. As a general trend, each alloy in this study exhibited increased strength with the refinement of $\sigma$-phase particles, though it is clear that aging temperature plays a role in the yield strength and failure strain of these alloys. The obvious deviations from the trend in Fig. 8(a) were the points of Alloy $18 \mathrm{Nb}+\mathrm{CrMo}$ aged at $1000^{\circ} \mathrm{C}$ and $18 \mathrm{Nb}+\mathrm{CrMo}$ aged at $1050^{\circ} \mathrm{C}$. These two samples were aged at different temperatures, but resulted in measurably the same particle sizes. The yield strength, however, was not entirely dependent on particle size and in this instance; the variation of this 
property with aging temperature (Fig. 8(b)) seems to have a more predictable dependence in these alloys. This is further evidenced by the results from Alloy $18 \mathrm{Nb}$ at $1100^{\circ} \mathrm{C}$ which deviate from the behavior of the other alloys. The particle size of $0.74 \mu \mathrm{m}$ in this alloy deviated significantly (not included in Fig. 8(a) and (c)) compared to the alloys which were able to successfully quench-in as the $\beta$-phase to room temperature prior to aging. These results suggest that the aging temperature is affecting the yield strength in ways other than controlling particle size including, $\gamma$-phase compositional changes and over-aging. So, while smaller particle size resulted in increased yield strength, there are other important factors as well in governing the yielding of these materials.

Fig. 8(c) and Fig. 8(d) show the variation of failure strain with particle size and aging temperature, respectively. For the samples that were aged from a quenched-in $\beta$-phase, the trends were generally consistent. As the particle size from a given alloy composition increased, the failure strain increased, and akin to the results presented in Fig. $8(\mathrm{a})$, the samples of $18 \mathrm{Nb}+\mathrm{CrMo}$ with larger particles $(0.24$ and $0.25 \mu \mathrm{m})$ resulted in vastly different failure strain despite the similar scale. Though again, when plotting versus aging temperature the trend was consistent for alloys $22+\mathrm{Cr}, 18 \mathrm{Nb}+\mathrm{CrMo}$ and $14+\mathrm{CrMo}$. Interestingly, Alloy $18 \mathrm{Nb}$ aged at $1100^{\circ} \mathrm{C}$ data in Fig. 8 (d) show a low relative failure strain despite a higher aging temperature, larger particle size, and lower $\sigma$-phase volume fraction, all of which correlate with increased strain to failure in alloys $22 \mathrm{Nb}+\mathrm{Cr}, 18 \mathrm{Nb}+\mathrm{CrMo}$ and $14+\mathrm{CrMo}$.

The interrupted compression results presented in Fig. 7 elucidate the nature of micro-crack initiation in the bulk of the $\gamma+\sigma$ microstructures for finer and coarser microstructures. Micro-cracks developed at a lower plastic strain of $1.4 \%$ in Alloy $14 \mathrm{Nb}+\mathrm{CrMo}$ aged at $1000^{\circ} \mathrm{C}$, and they were primarily located at the interface of the $\gamma$-matrix and $\sigma$-particles and less so in the $\gamma$-matrix, as shown in Fig. 7(c). No cracking of the $\sigma$-phase was observed in this alloy. Alloy $18 \mathrm{Nb}$ aged at $1100^{\circ} \mathrm{C}$ began micro-cracking at a plastic strain of 3.5\%, but cracks were primarily observed within the coarser $\sigma$ - 
phase particles and not at the matrix/particle interface or within the $\gamma$-matrix at this strain level. These observations show that the reduction of $\sigma$-phase particle size from micron to submicron scale has shifted the fracture initiation away from $\sigma$-phase fracture initiation seen in coarser, high $\sigma$ alloys [14] ( $\sigma$-phase volume fraction of 0.5 ) and, thus, to a matrix/particle interface fracture initiation. Additionally, while the alloy with the finer microstructure developed micro-cracks at lower strain (1.4\% versus $3.5 \%)$, the stress level when the cracks developed was approximately $100 \mathrm{MPa}$ higher for the refined structure. This higher stress level and the move away from crack initiation within the $\sigma$ phase particles suggests greater strain distribution throughout the matrix and lesser stress build up in the brittle $\sigma$-phase for the finer microstructure.

The proposed effect of microstructural scale on the ductility of the alloys was challenged by the results produced from these samples. The refined microstructures were expected to result in enhanced plasticity. The results from this study suggest that the relative low failure strain in refined microstructures was owed to damage and fracture initiation at prior $\beta$-phase grain boundaries, the yield strength of the aged material, and the ultimate compressing strength (UCS) of the samples.

\subsection{Comparison of $\gamma+\sigma$ alloys to other novel $\gamma$-based alloys}

It is important to understand where the properties of these alloys lie with respect to other $\gamma$ based alloys being explored for advancement of aerospace turbines. Fig. 9 is a plot of failure strain versus strength under compression for several TiAl-based alloys [11, 12, 25, 31, 32] including alloys from this study. The compressive strength of the $\gamma+\sigma$ alloys are in the upper range of mechanically alloyed TiAl composites (dashes and circles in Fig. 9) and are approaching the compressive ductility of some advanced 4822 and high $\mathrm{Nb}$ alloys (diamonds and triangles, respectively, in Fig. 9). It is important to note that the 4822 and High Nb alloys in Fig. 9 have been thermomechanically processed and the alloys in this study are directly tested from as-cast material. The ability to enhance $\gamma+\sigma$ alloys 
has several attractive dimensions, including the capability of being thermomechanically processed due to the presence of the $\beta$-phase at elevated temperatures, further microstructural control through varying aging times and temperatures, means of microstructural refinement such as straining prior to aging, and even the possibility of growing of single crystals to eliminate the deleterious effect of the prior $\beta$ grain boundaries on compressive ductility.

\section{Summary}

Four alloys with $\gamma+\sigma$ microstructures were produced through a solutionizing+WQ heat treatment followed by aging. The strength and strain to failure was governed macroscopically by the existence of large prior $\beta$ grains for samples which effectively quenched in the $\beta$-phase prior to aging. Micro-crack initiation occurred on the $\gamma / \sigma$ interfaces for these alloys with significantly refined $\sigma$ phase, and in the coarse $\sigma$-particles of Alloy $18 \mathrm{Nb}-1100$.

1. In the fine $\gamma+\sigma$ microstructures, microcracking occurred predominately at the $\gamma / \sigma$ interfaces. In Alloy $18 \mathrm{Nb}$ microcracking occurred in the coarse $\sigma$-phase.

2. Microstructural parameters including volume fraction, $\sigma$ particle size and spacing all played a role in the resulting yield strength. The strength increased with decreasing particle size and spacing and, generally, increased as the volume fraction of the hard brittle $\sigma$-phase increased.

3. The failure strain of these samples was affected by the volume fraction of the $\sigma$-phase and scale of the overall microstructure.

4. In alloys with refined microstructures, the fracture was more dominated by the existence of prior beta grain boundaries than by the hard, brittle $\sigma$-phase.

\section{References}


[1] X. Wu, Review of alloy and process development of TiAl alloys, Intermetallics 14(10-11) (2006) 1114-1122.

[2] Y.W. Kim, Ordered intermetallic alloys 3. gamma-titanium aluminides, Jom-Journal of the Minerals Metals \& Materials Society 46(7) (1994) 30-39.

[3] F. Appel, R. Wagner, Microstructure and deformation of two-phase $\gamma$-titanium aluminides, Materials Science and Engineering: R: Reports 22(5) (1998) 187-268.

[4] M. Yamaguchi, D.R. Johnson, H.N. Lee, H. Inui, Directional solidification of TiAl-base alloys, Intermetallics 8(5-6) (2000) 511-517.

[5] M. Yamaguchi, H. Inui, K. Ito, High-temperature structural intermetallics, Acta Materialia 48(1) (2000) 307-322.

[6] Y.-W. Kim, Effects of microstructure on the deformation and fracture of $\gamma$-TiAl alloys, Materials Science and Engineering: A 192-193, Part 2 (1995) 519-533.

[7] Y.W. Kim, Strength and ductility in TiAl alloys, Intermetallics 6(7-8) (1998) 623-628.

[8] K.S. Chan, Y.W. Kim, Influence of microstructure on crack-tip micromechanics and fracture behaviors of a 2-phase TiAl alloy, Metallurgical Transactions a-Physical Metallurgy and Materials Science 23(6) (1992) 1663-1677.

[9] K.S. Chan, Y.W. Kim, Effects of lamellae spacing and colony size on the fracture resistance of a fully-lamellar TiAl alloy, Acta Metallurgica et Materialia 43(2) (1995) 439-451.

[10] J. Lapin, L. Ondrus, O. Bajana, Effect of Al2O3 particles on mechanical properties of directionally solidified intermetallic Ti-46Al-2W-0.5Si alloy, Materials Science and Engineering aStructural Materials Properties Microstructure and Processing 360(1-2) (2003) 85-95.

[11] K.P. Rao, J.B. Zhou, Characterization and mechanical properties of in situ synthesized Ti5Si3/TiAl composites, Materials Science and Engineering a-Structural Materials Properties Microstructure and Processing 356(1-2) (2003) 208-218.

[12] R. Bohn, T. Klassen, R. Bormann, Room temperature mechanical behavior of silicon-doped TiAl alloys with grain sizes in the nano- and submicron-range, Acta Materialia 49(2) (2001) 299-311. [13] B.J.G. deAragao, F. Ebrahimi, High temperature deformation of Nb-Ti-Al alloys with sigma+gamma microstructure, Materials Science and Engineering a-Structural Materials Properties Microstructure and Processing 208(1) (1996) 37-46.

[14] F. Ebrahimi, J.R. Castillogomez, The Effect of Plastic-Deformation on Fracture Morphology of the Sigma-Phase in the Nb-Ti-Al System, Acta Metallurgica Et Materialia 40(6) (1992) 1409-1416. [15] F. Ebrahimi, D.T. Hoelzer, J.R. Castillogomez, Fracture-toughness of sigma $+x$ microstructures in the Nb-Ti-Al system, Materials Science and Engineering a-Structural Materials Properties Microstructure and Processing 171(1-2) (1993) 35-45.

[16] F. Ebrahimi, B.J.G. Dearagao, J.R. Castillogomez, Evaluation of Fracture-Toughness of Duplex Microstructures by an Indentation Technique, Materials Science and Engineering a-Structural Materials Properties Microstructure and Processing 177(1-2) (1994) L7-L10.

[17] S. Goyel, O. Rios, M.S. Kesler, F. Ebrahimi, Two-step nucleation of the $\gamma$-phase in a Ti-45Al$18 \mathrm{Nb}$ alloy, Intermetallics 18(8) (2010) 1491-1497.

[18] M.S. Kesler, S. Goyel, O. Rios, D.M. Cupid, H.J. Seifert, F. Ebrahimi, A study of phase transformation in a TiAlNb alloy and the effect of $\mathrm{Cr}$ addition, Materials Science and Engineering aStructural Materials Properties Microstructure and Processing 527(12) (2010) 2857-2863.

[19] O. Rios, S. Goyel, M.S. Kesler, D.M. Cupid, H.J. Seifert, F. Ebrahimi, An evaluation of hightemperature phase stability in the Ti-Al-Nb system, Scripta Materialia 60(3) (2009) 156-159. 
[20] J.D.H. Paul, F. Appel, R. Wagner, The compression behaviour of niobium alloyed gammatitanium aluminides, Acta Materialia 46(4) (1998) 1075-1085.

[21] H. Clemens, H.F. Chladil, W. Wallgram, G.A. Zickler, R. Gerling, K.D. Liss, S. Kremmer, V. Guether, W. Smarslyg, In and ex situ investigations of the beta-phase in a $\mathrm{Nb}$ and Mo containing gamma-TiAl based alloy, Intermetallics 16(6) (2008) 827-833.

[22] W.J. Zhang, F. Appel, Effect of Al content and $\mathrm{Nb}$ addition on the strength and fault energy of TiAl alloys, Materials Science and Engineering: A 329-331 (2002) 649-652.

[23] W.J. Zhang, S.C. Deevi, G.L. Chen, On the origin of superior high strength of Ti-45Al-10Nb alloys, Intermetallics 10(5) (2002) 403-406.

[24] Y.H. Wang, J.P. Lin, Y.H. He, X. Lu, Y.L. Wang, G.L. Chen, Microstructure and mechanical properties of high $\mathrm{Nb}$ containing TiAl alloys by reactive hot pressing, Journal of Alloys and Compounds 461(1-2) (2008) 367-372.

[25] X. Lu, X.B. He, B. Zhang, L. Zhang, X.H. Qu, Z.X. Guo, Microstructure and mechanical properties of a spark plasma sintered Ti-45Al-8.5Nb-0.2W-0.2B-0.1Y alloy, Intermetallics $17(10)$ (2009) 840-846.

[26] D.M. Cupid, O. Fabrichnaya, O. Rios, F. Ebrahimi, H.J. Seifert, Thermodynamic re-assessment of the Ti-Al-Nb system, International Journal of Materials Research 100(2) (2009) 218-233.

[27] G.E. Bean, M.S. Kesler, M.V. Manuel, Effect of $\mathrm{Nb}$ on phase transformations and microstructure in high $\mathrm{Nb}$ titanium aluminides, Journal of Alloys and Compounds 613(0) (2014) 351-356.

[28] E.E. Underwood, Quantitative Stereography, Addison-Wesley Pub. Co., Reading, Mass., 1970. [29] J.C. Mishurda, V.K. Vasudevan, An estimate of the kinetics of the $\beta 0$ to orthorhombic phase transformation in the Nb-Ti-Al system, Scripta Materialia 45(6) (2001) 677-684.

[30] J.R. Castillo-Gomez, Development of high temperature niobium based alloys, Materials Science and Engineering, University of Florida, Gainesville, Fl, 1990.

[31] Y.H. Wang, J.P. Lin, Y.H. He, X. Lu, Y.L. Wang, G.L. Chen, Microstructure and mechanical properties of high $\mathrm{Nb}$ containing TiAl alloys by reactive hot pressing, Journal of Alloys and Compounds 461(1-2) (2008) 367-372.

[32] M. Usta, H. Wolfe, D.J. Duquette, N.S. Stoloff, R.N. Wright, Thermo-mechanical grain refinement in gamma $(\gamma)$ based TiAl intermetallics, Materials Science and Engineering: A 359(1-2) (2003) 168-177. 


\section{ACKNOWLEDGEMENTS}

This research was supported by the National Science Foundation under the grant number DMR0856622.

\section{TABLES}

Table 1: Phases of interest for the alloys in this work.

Table 2. The nominal and actual composition of each alloy as measured by EPMA.

Table 3. Microstructural parameters of the four microstructures tested under compression. Standard deviations of $\pm 1 \sigma$ are provided.

Table 4. Mechanical properties of Ti-Al-Nb(Cr,Mo) alloys tested under compression, where FIGURES

Figure 1. Isopleth section of the Ti-Al-Nb ternary at 45 at.\% $\mathrm{Al}$, with relevant alloy compositions indicated [26].

Figure 2. Optical micrographs and XRD profiles of solutionized+WQ alloys: a), b) $22 \mathrm{Nb}+\mathrm{Cr}$ at $1400^{\circ} \mathrm{C}$; c), d) $14 \mathrm{Nb}+\mathrm{CrMo}$ at $1400^{\circ} \mathrm{C}$; e), f) $14 \mathrm{Nb}+\mathrm{CrMo}$; g), h) $18 \mathrm{Nb}$ at $1500^{\circ} \mathrm{C}$

Figure 3. BSE micrographs of aged $\gamma+\sigma$ microstructures in alloys: a,b) $22 \mathrm{Nb}+\mathrm{Cr}$; c,d) $18 \mathrm{Nb}+\mathrm{CrMo}$; e,f) $14 \mathrm{Nb}+\mathrm{CrMo}$; g) $18 \mathrm{Nb}$. (All for 2 hours)

Figure 4: XRD pattern of $22 \mathrm{NB}+\mathrm{Cr}$ after aging at $1050^{\circ} \mathrm{C}$. Note that the previously single phase $\beta$ microstructure (Figure $2 \mathrm{a}$ and $\mathrm{b}$ ) has developed into $\mathrm{a} \gamma+\sigma$ microstructure.

Figure 5. True stress-strain curves for alloys: a) $22 \mathrm{Nb}+\mathrm{Cr}$; b) $22 \mathrm{Nb}+\mathrm{Cr}$; c) $14 \mathrm{Nb}+\mathrm{CrMo}$; d) $18 \mathrm{Nb}$. Figure 6. Compilation of optical micrographs and an SE micrograph, respectively, of the macroscopic fracture path originating at the prior $\beta$ grain boundaries and propagating via a) slabbing in a sample of Alloy $22 \mathrm{Nb}+\mathrm{Cr}-1050$, or b) following adjacent to the prior grain boundaries in Alloy $22 \mathrm{Nb}+\mathrm{Cr}-865$. The inset in Fig. 6(b) reveals a tortuous fracture surface. 
Figure 7. Interrupted stress-strain curves (black) overlaid on original curves (gray) loaded to fracture $(a, b)$, and SEM micrographs $(c, d)$ showing relative sizes of the $\sigma$-phase and the microcracking that ensues in alloys $14 \mathrm{Nb}+\mathrm{CrMo}$ and $18 \mathrm{Nb}$, respectively. In Alloy $18 \mathrm{Nb}$, (b), a second loading was necessary to achieve microcracking in the bulk of the microstructure structure.

Figure 8. The plots of yield strength vs. a) particle size of the $\sigma$-phase and b) aging temperature; and plastic strain to failure vs. c) particle size of the $\sigma$-phase and d) aging temperature for alloys $18 \mathrm{Nb}$, $22 \mathrm{Nb}+\mathrm{Cr}, 18 \mathrm{Nb}+\mathrm{CrMo}$, and $14 \mathrm{Nb}+\mathrm{CrMo}$.

Figure 9. A plot of plastic failure strain vs. yield strength for a number of TiAl based alloys tested under compression including the four microstructures tested in this study. 


\begin{tabular}{|c|c|c|c|}
\hline Phase & gamma $(\mathbf{\gamma})$ & sigma $(\boldsymbol{\sigma})$ & beta $(\boldsymbol{\beta})$ \\
\hline Nominal Chemistry & $\mathrm{TiAl}$ & $\mathrm{Nb}_{2} \mathrm{Al}$ & $\mathrm{TiAl}_{\mathrm{x}} \mathrm{Nb}_{(0.5-\mathrm{x})}$ \\
\hline Crystal Structure & $\begin{array}{c}\text { Face-Centered } \\
\text { Tetragonal }\end{array}$ & $\begin{array}{c}\text { Complex } \\
\text { Unit Cell }\end{array}$ & $\mathrm{BCC}$ \\
\hline Atoms in Unit Cell & 4 & 30 & 2 \\
\hline
\end{tabular}




\begin{tabular}{|c|c|c|c|c|c|}
\hline \multirow{2}{*}{$\begin{array}{c}\text { Alloy names and } \\
\text { nominal composition } \\
\text { (at\%) }\end{array}$} & \multicolumn{5}{|c|}{ Actual Composition (at\%) } \\
\cline { 2 - 6 } & $\mathrm{Ti}$ & $\mathrm{Al}$ & $\mathrm{Nb}$ & $\mathrm{Cr}$ & $\mathrm{Mo}$ \\
\hline $\begin{array}{c}22 \mathrm{Nb}+\mathrm{Cr} \\
(\mathrm{Ti}-45 \mathrm{Al}-22 \mathrm{Nb}-5 \mathrm{Cr})\end{array}$ & 28.9 & 43.5 & 22.6 & 5.0 & --- \\
\hline $\begin{array}{c}18 \mathrm{Nb}+\mathrm{CrMo} \\
(\mathrm{Ti}-45 \mathrm{Al}-18 \mathrm{Nb}-5 \mathrm{Cr}-1 \mathrm{Mo})\end{array}$ & 30.7 & 45.5 & 17.9 & 5.0 & 0.9 \\
\hline $\begin{array}{c}14 \mathrm{Nb}+\mathrm{CrMo} \\
(\mathrm{Ti}-45 \mathrm{Al}-14 \mathrm{Nb}-5 \mathrm{Cr}-1 \mathrm{Mo})\end{array}$ & 34.9 & 44.7 & 14.3 & 5.1 & 1.0 \\
\hline $\begin{array}{c}18 \mathrm{Nb} \\
(\mathrm{Ti}-45 \mathrm{Al}-18 \mathrm{Nb})\end{array}$ & 37.0 & 44.7 & 18.3 & --- & -- \\
\hline
\end{tabular}




\begin{tabular}{|c|c|c|c|c|c|}
\hline Alloys & $\begin{array}{c}\text { Aging } \\
\text { Temperature } \\
\text { (Celcius) }\end{array}$ & $\begin{array}{c}\text { Volume } \\
\text { Fraction } \\
\sigma \text {-phase }\end{array}$ & $\begin{array}{c}\text { Mean } \\
\text { Random } \\
\text { Spacing, } \\
\sigma_{\mathrm{r}} \\
(\mu \mathrm{m})\end{array}$ & $\begin{array}{c}\text { Mean-free } \\
\text { Path, } \\
\lambda \\
(\mu \mathrm{m})\end{array}$ & $\begin{array}{c}\text { Mean } \\
\text { Diameter } \\
(\mu \mathrm{m})\end{array}$ \\
\hline $\begin{array}{c}22 \mathrm{Nb}+ \\
\mathrm{Cr}\end{array}$ & 865 & $0.30 \pm 0.04$ & $0.47 \pm 0.09$ & $0.33 \pm 0.07$ & 0.14 \\
\hline $18 \mathrm{Nb}+$ & 1050 & $0.31 \pm 0.02$ & $0.91 \pm 0.11$ & $0.62 \pm 0.09$ & $0.29^{*}$ \\
\hline $\mathrm{CrMo}$ & 1000 & $0.22 \pm 0.02$ & $1.09 \pm 0.09$ & $0.86 \pm 0.09$ & 0.23 \\
\hline $14 \mathrm{Nb}+$ & 1050 & $0.22 \pm 0.01$ & $1.12 \pm 0.17$ & $0.88 \pm 0.14$ & 0.24 \\
\hline $\mathrm{CrMo}$ & 1000 & $0.13 \pm 0.01$ & $1.05 \pm 0.18$ & $0.91 \pm 0.16$ & 0.14 \\
\hline $18 \mathrm{Nb}$ & 1050 & $0.13 \pm 0.01$ & $1.66 \pm 0.30$ & $1.45 \pm 0.29$ & 0.21 \\
\hline
\end{tabular}

${ }^{*}$ Due to the elongated, connected $\sigma$-phase in this specimen, the mean diameter represents a relative coarsening of the $\sigma$-phase rathar than the actual particle diameter 


\begin{tabular}{|c|c|c|c|c|}
\hline Alloys & $\begin{array}{c}\text { Aging } \\
\text { Temperature } \\
\text { (Celcius) }\end{array}$ & $\begin{array}{c}\text { Yield } \\
\text { Strength, } \\
\sigma_{y} \\
(\text { MPa) }\end{array}$ & $\begin{array}{c}\text { Ultimate } \\
\text { Compressive } \\
\text { Strength, } \\
\sigma_{\mathrm{UCS}} \\
(\mathrm{MPa})\end{array}$ & $\begin{array}{c}\text { Plastic } \\
\text { Strain, } \\
\varepsilon_{\mathrm{p}} \\
(\%)\end{array}$ \\
\hline $22 \mathrm{Nb}+\mathrm{Cr}$ & $\begin{array}{r}865 \\
1050\end{array}$ & $\begin{array}{l}1917 \\
1922 \\
1483 \\
1468 \\
\end{array}$ & $\begin{array}{l}2150 \\
2164 \\
2088 \\
2037 \\
\end{array}$ & $\begin{array}{l}1.5 \\
1.2 \\
4.6 \\
5.1 \\
\end{array}$ \\
\hline $18 \mathrm{Nb}+\mathrm{CrMo}$ & $\begin{array}{l}865 \\
1000 \\
1050\end{array}$ & $\begin{array}{l}2140 \\
1643 \\
1513 \\
1108 \\
1011 \\
\end{array}$ & $\begin{array}{l}2643 \\
2567 \\
2205 \\
2687 \\
3037 \\
\end{array}$ & $\begin{array}{c}6.7 \\
15.6 \\
13.9 \\
27.2 \\
35.0\end{array}$ \\
\hline 14Nb+CrMo & $\begin{array}{r}865 \\
1000 \\
1050\end{array}$ & $\begin{array}{c}1653 \\
1342 \\
1336 \\
909\end{array}$ & $\begin{array}{l}2514 \\
2274 \\
2139 \\
3106\end{array}$ & $\begin{array}{l}10.5 \\
12.4 \\
12.5 \\
31.8\end{array}$ \\
\hline $18 \mathrm{Nb}$ & 1100 & $\begin{array}{l}1112 \\
1092\end{array}$ & $\begin{array}{l}2321 \\
2259\end{array}$ & $\begin{array}{l}20.2 \\
22.0\end{array}$ \\
\hline
\end{tabular}




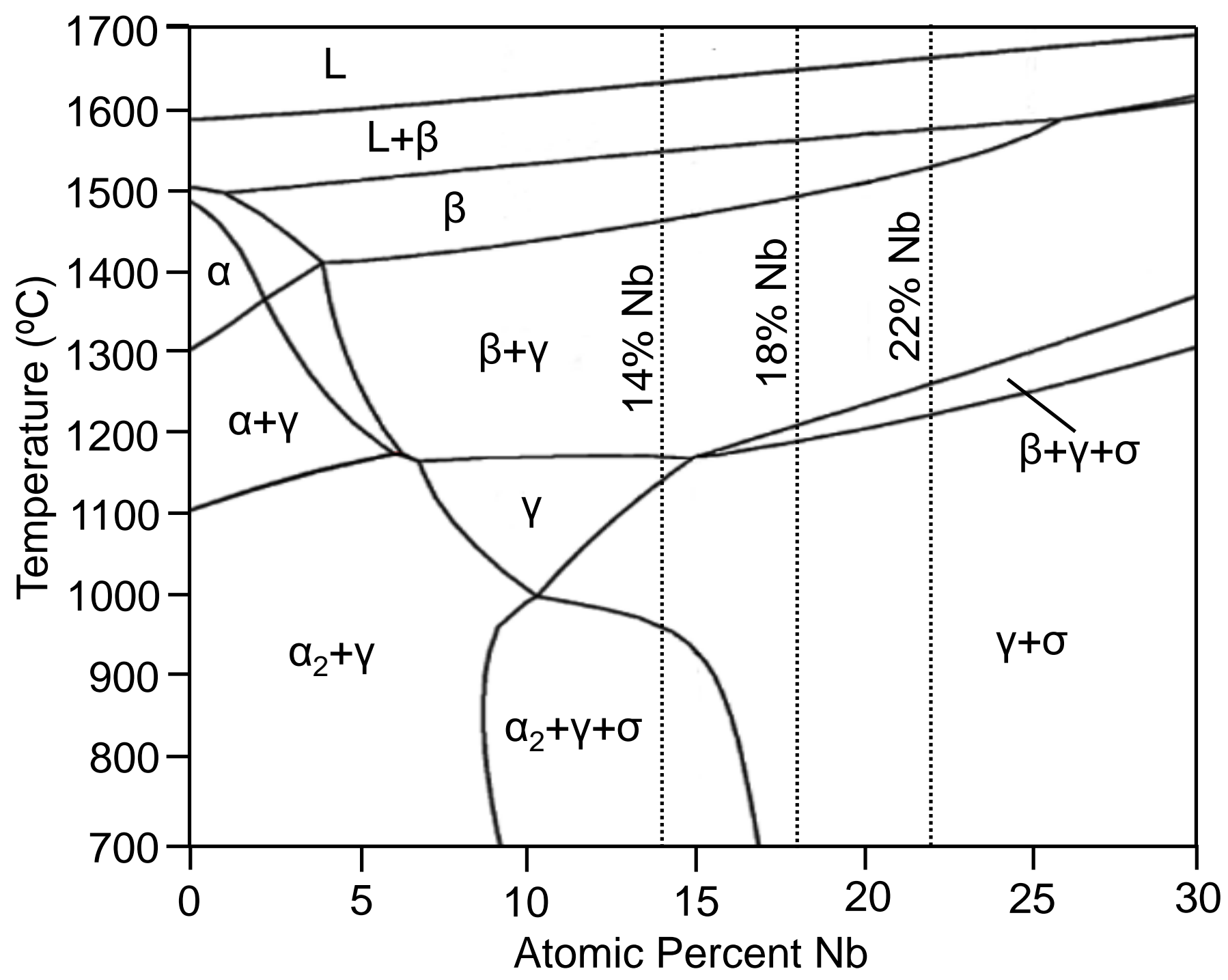




\section{a) $22 \mathrm{Nb}+\mathrm{Cr}$}

\section{$250 \mu \mathrm{m}$}

c) $18 \mathrm{Nb}+\mathrm{CrMo}$

\section{$250 \mu \mathrm{m}$}

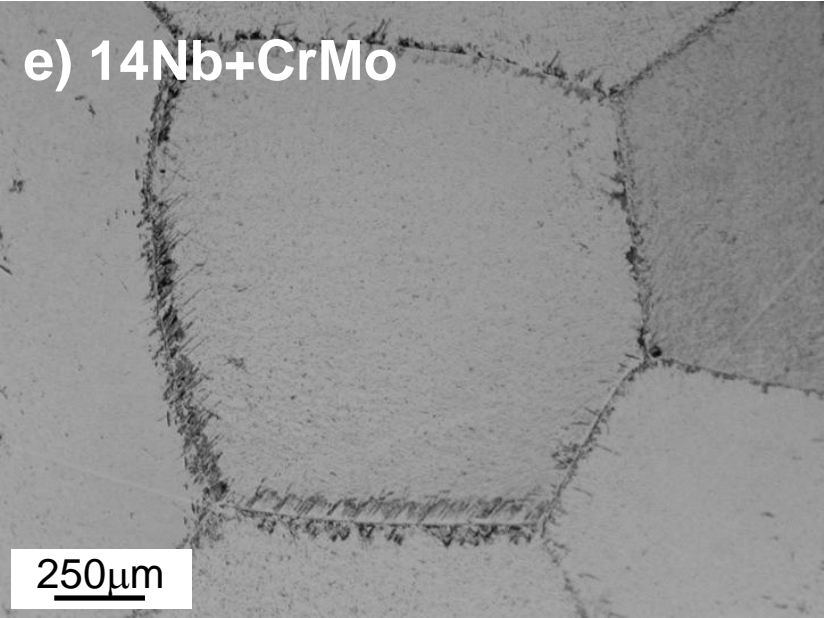

\section{g) $18 \mathrm{Nb}$}
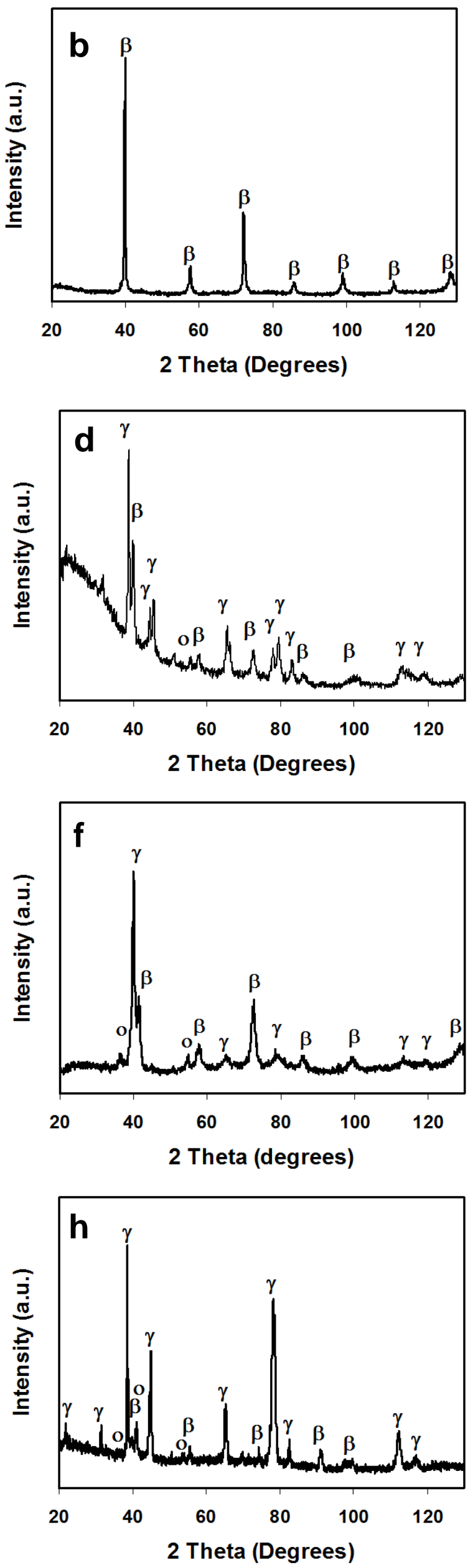
Figure 3
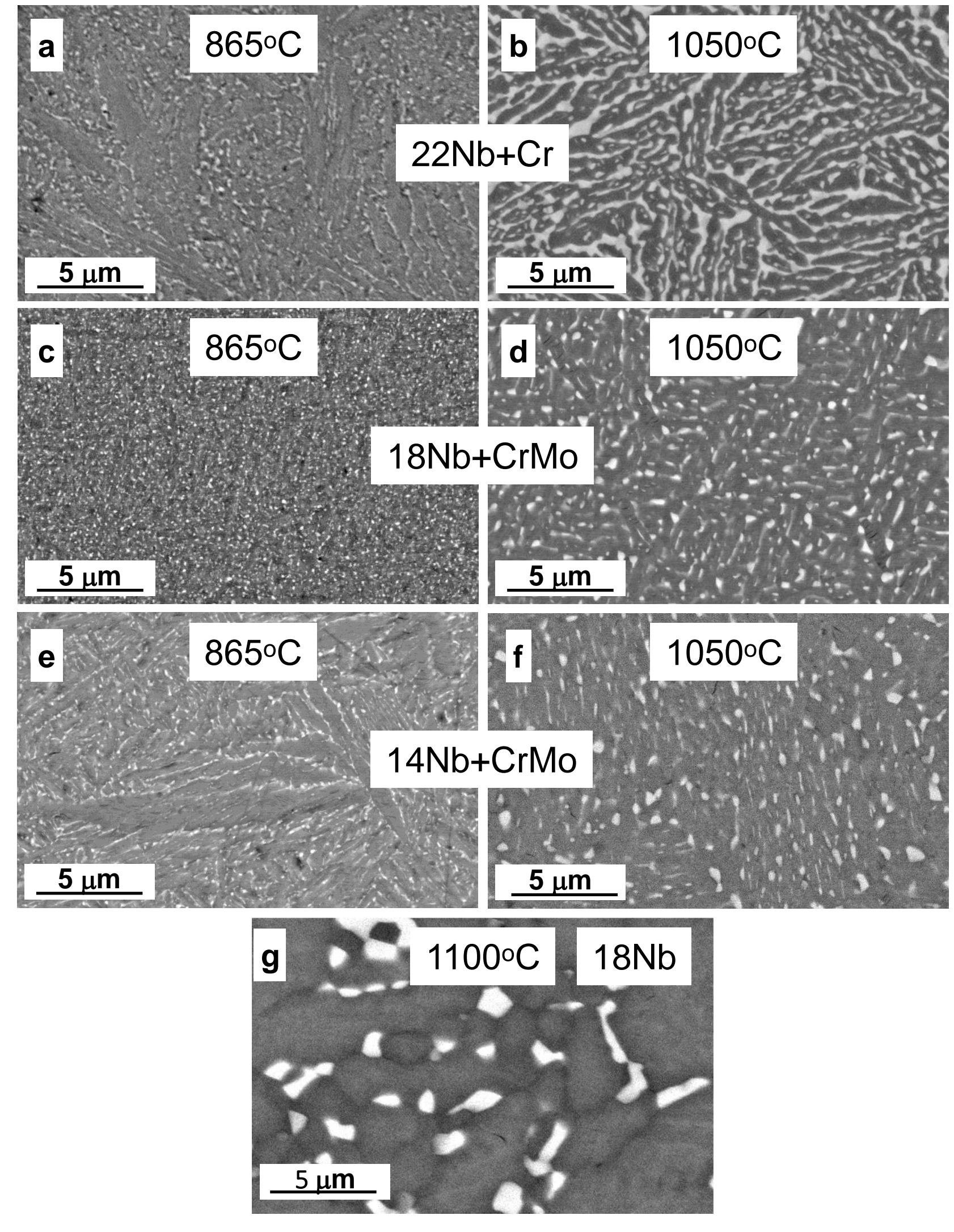

Fur

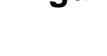

.

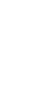

.




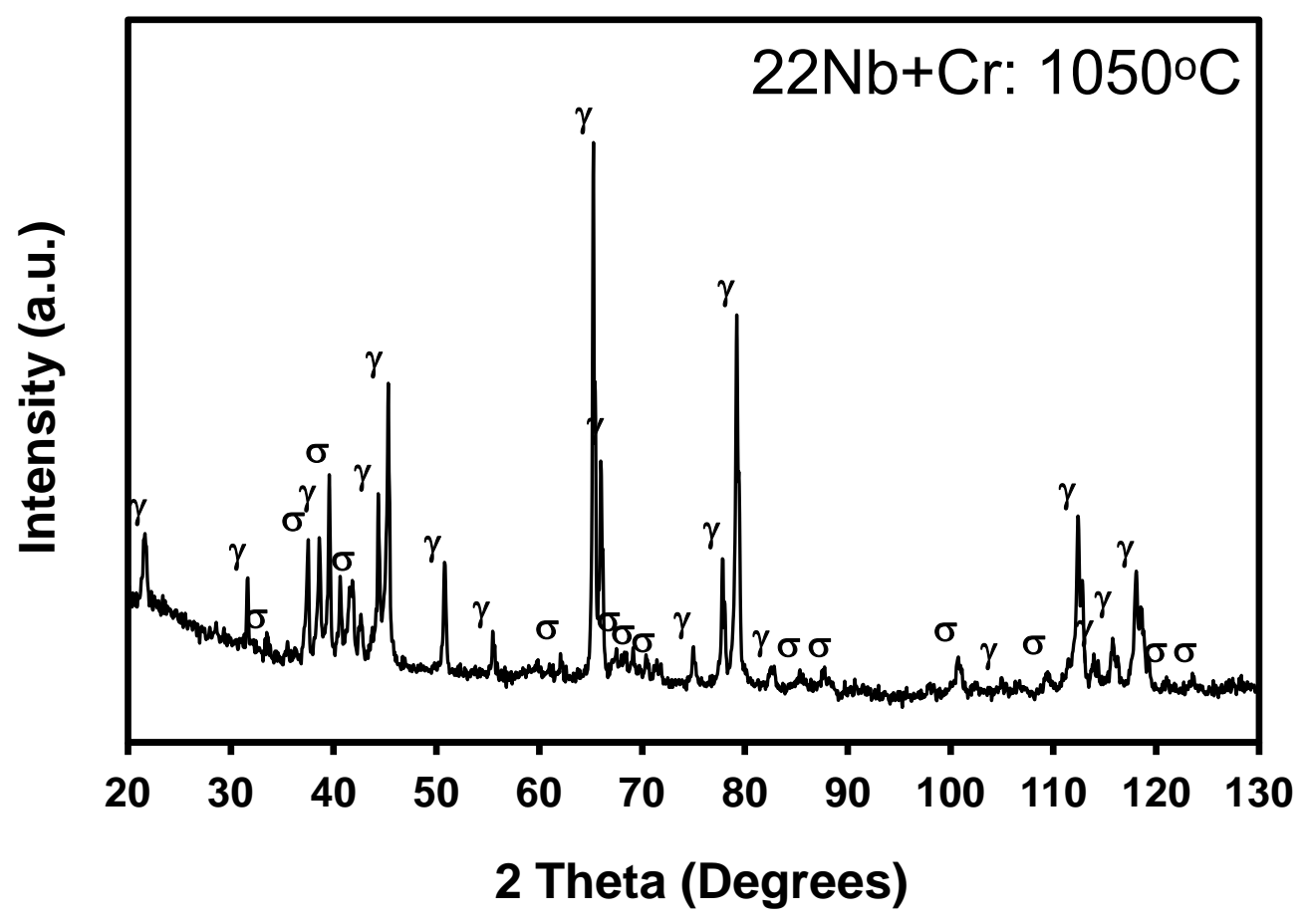



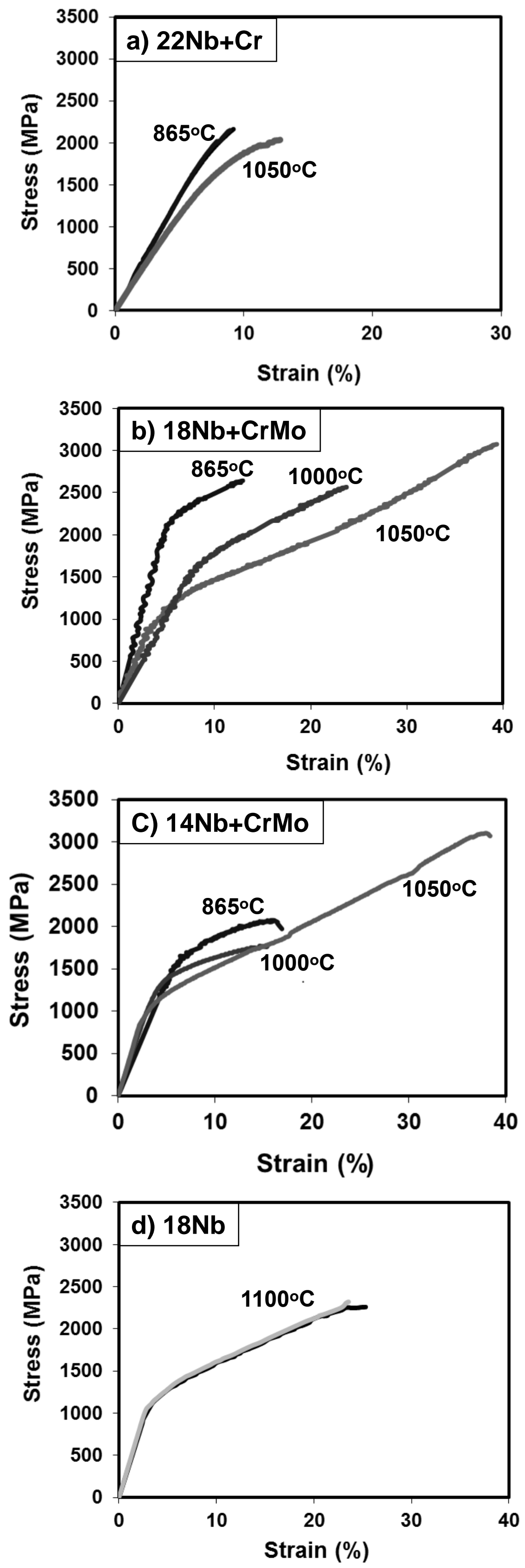
Figure 6
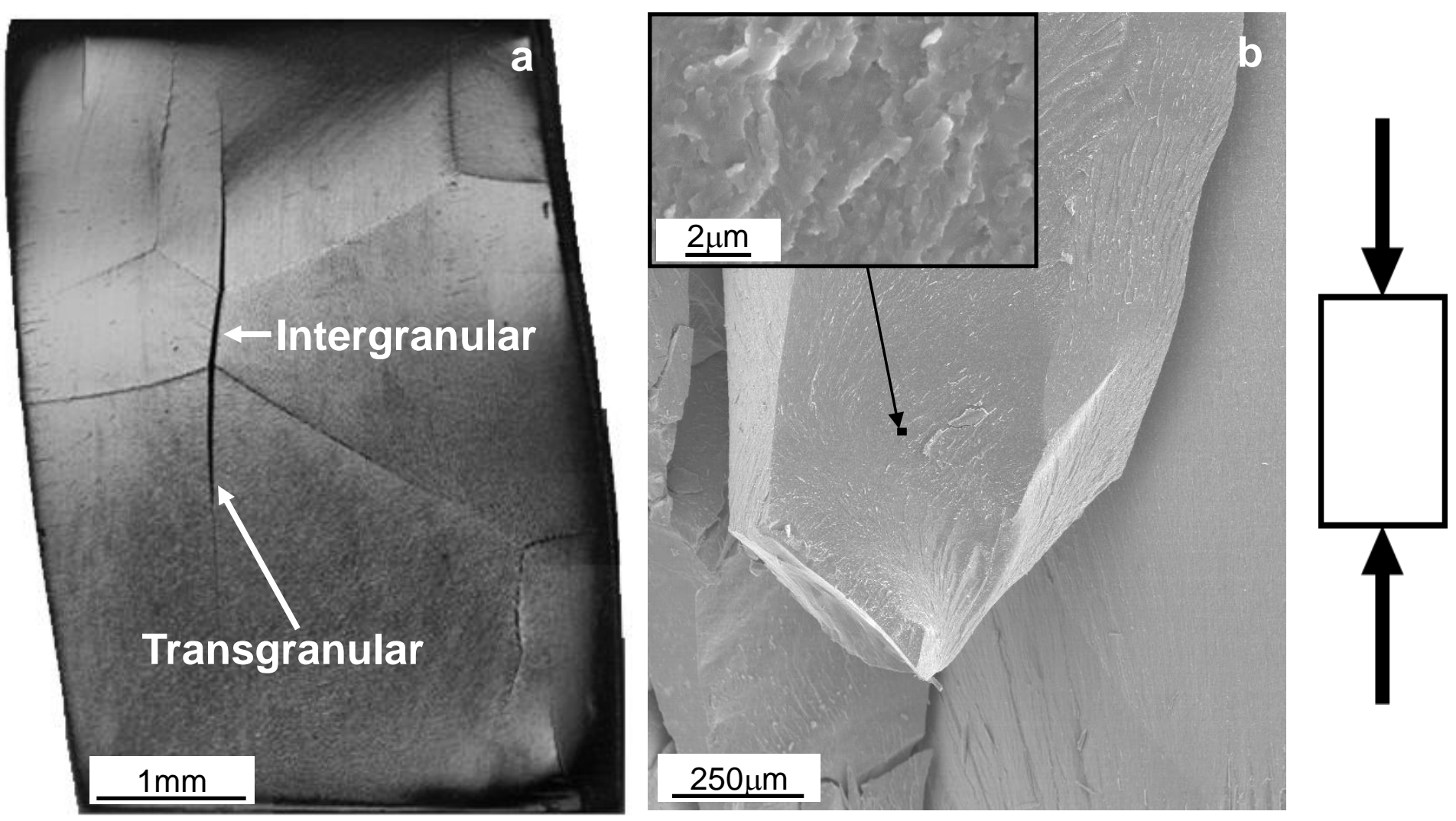

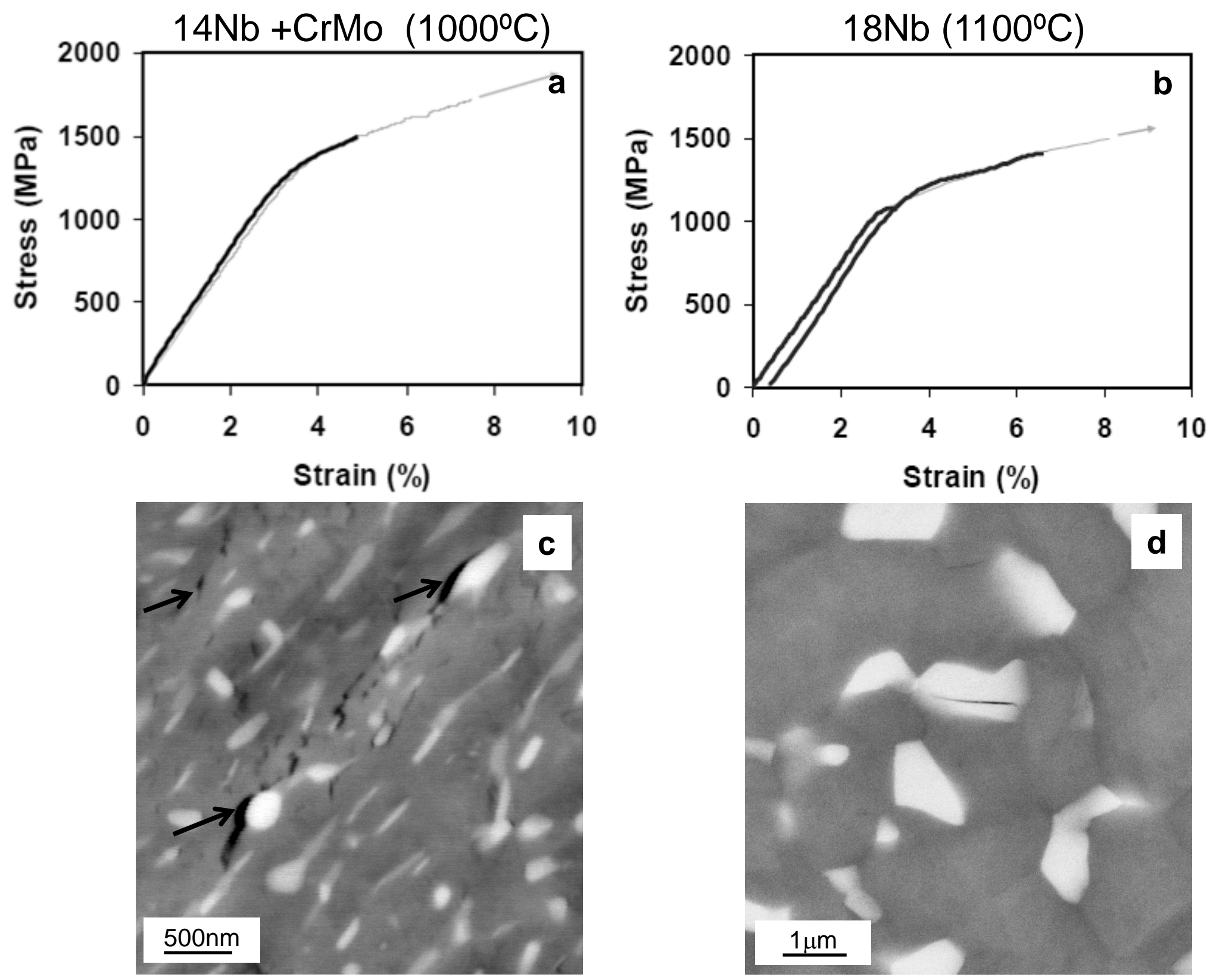

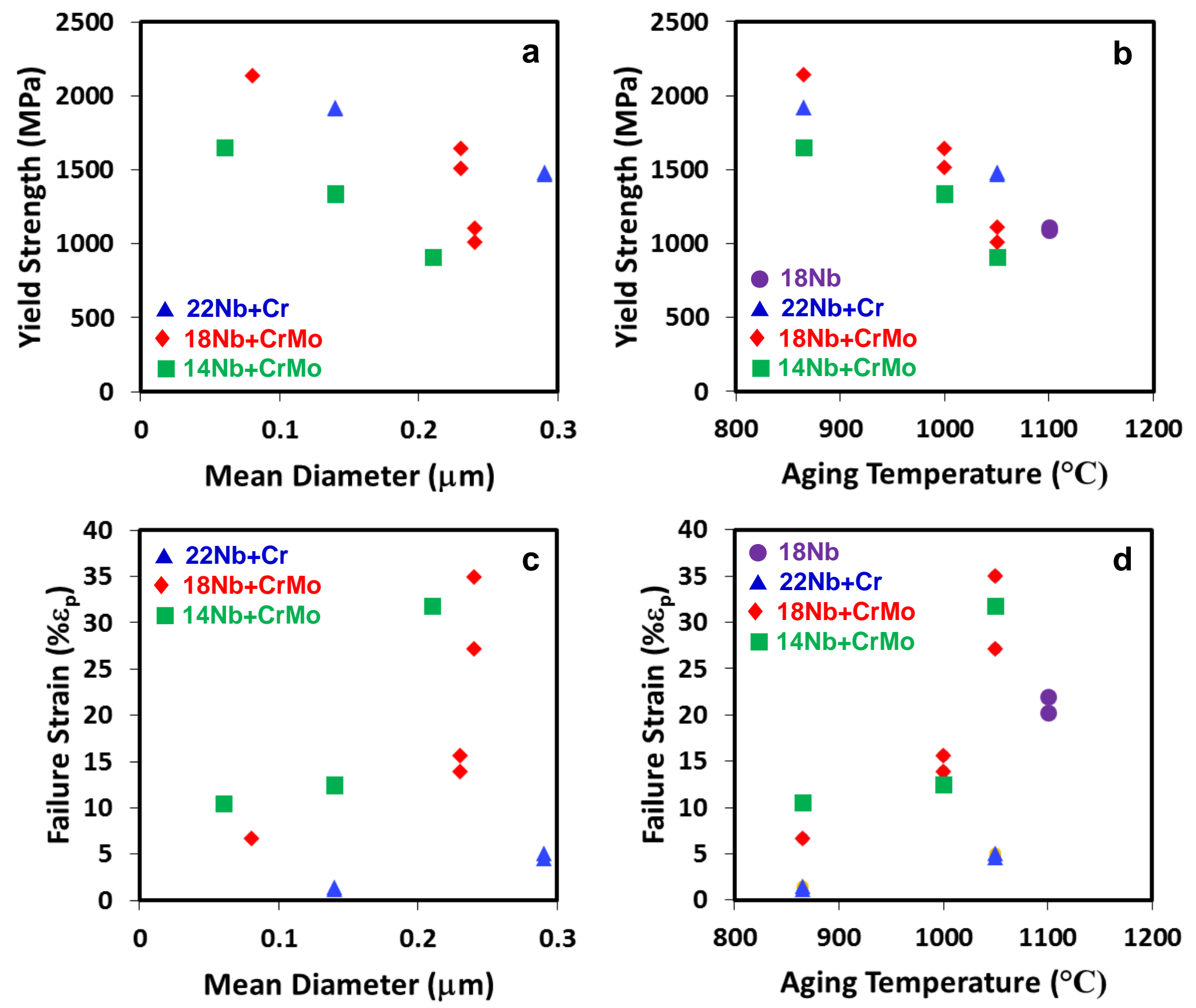
Figure 9

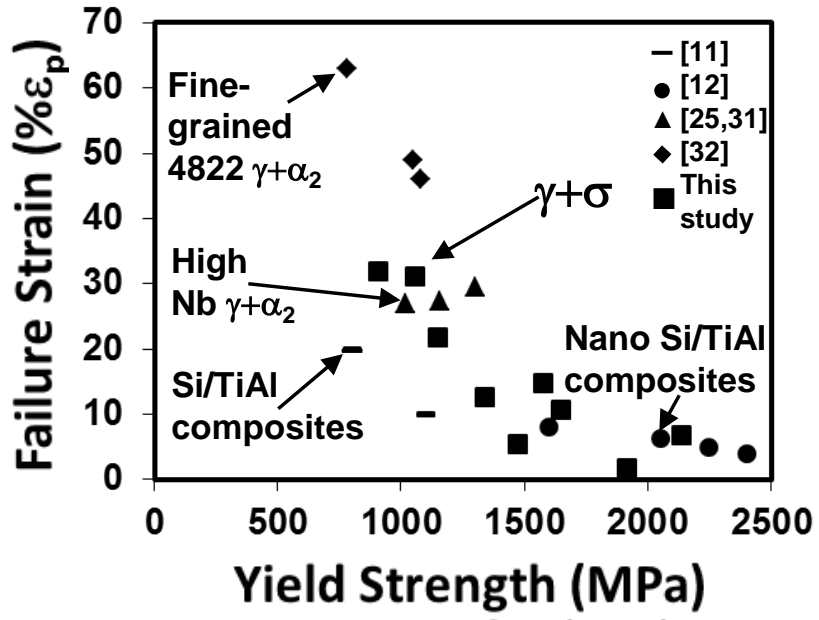

